\title{
Prevalence and factors associated with late antenatal care visit among pregnant women in Lushoto, Tanzania
}

FLORA NJIKU', HERMAN L. WELLA, ADELLAH SARIAH ${ }^{1}$ and JOYCE PROTAS ${ }^{1 *}$

'Hubert Kairuki Memorial University, Faculty of Nursing, Dar es Salaam, Tanzania

${ }^{2}$ Muhimbili National Hospital, Dar es Salaam, Tanzania

\begin{abstract}
Background: Adequate utilization of antenatal health care services is associated with improved maternal and neonatal health outcomes. The World Health Organization recommends pregnant women to attend antenatal care services as early as in the first trimester. However, many women due to various reasons fail to meet the recommendations. The objective of this study was to determine the prevalence and factors associated with late antenatal booking among pregnant women in Lushoto district of north-eastern Tanzania.

Methods: This hospital based cross sectional study involved pregnant women and was conducted in August-September 2015. A standardized questionnaire was used to obtain participants demographic characteristics and obstetrics history. Data analysis was done using (SPSS) and relationship between outcome variables and exposure variable was done using Chi-square test. Multivariate logistic regression was used to measure the association.

Results: A total of 240 participants were involved in the study. Out of these, 169 (70.4\%) participants booked late for antenatal care (ANC) services. Delayed booking was mainly associated with not being married (AOR=3.08; 95\% Cl 1.149-8.275; $\mathrm{P}$ value $=0.025)$ and unemployment $(\mathrm{AOR}=4.28 ; 95 \% \mathrm{Cl}$ 2.11-8.679; $p$ value $=0.000)$

Conclusion: Late first antenatal clinic visit was high in Lushoto, and was highly associated with unmarried and unemployment status. Therefore, provision of continuous health education and community sensitization on the importance of timely seeking ANC services should be strengthened.
\end{abstract}

Keywords: pregnancy, antenatal, visit, delayed booking, factors, Tanzania

\section{Introduction}

Maternal mortality is a public health concern worldwide, and especially so in developing countries (Nisar \& White,2003; Collin et al., 2007; Say et al., 2014). Antenatal care (ANC) services and delivery care are key strategies to reduce maternal death (Ebu \& Gross, 2015). Generally, ANC service is intended to provide safe pregnancy and delivery, as well as health awareness on the benefits of antenatal care services (Uji et al., 2017). Antenatal care provides the opportunity to monitor pregnancy, detect and treat anomalies of pregnancy and to deliver preventive health services such as immunization and HIV testing and counselling (Gross et al., 2012; Kisuule et al., 2013). For a pregnant woman to fully benefit these services, she must attend to the ANC timely and at the frequency as recommended by the World Health Organization (Gross et al., 2012). In its new strategy of Focused Antenatal Care (FANC), WHO recommends a minimum of four visits in low risk pregnancies and suggests the first visit to be as early as possible preferably in the first trimester (8-12 weeks of pregnancy). During this visit pregnancy and expected date of delivery (EDD) are confirmed. The last visit is recommended to be at around 37 weeks or near expected date of birth to ensure appropriate advice and care are provided ( $\mathrm{MoH}, 2002$; WHO, 2006; Ornella et al., 2014).

Prevalence of ANC visit varies among regions. Globally, the prevalence of antenatal visit is 97\%, and low in sub-Saharan Africa especially in Congo (Ebu \& Gross, 2015). In Tanzania the prevalence of antenatal visit has gone up from 90\% (TDHS, 2011) to 98\%(TDHS-MIS, 2016). Despite this increase, only $24 \%$ of pregnant were reported to begin their ANC visit during the first trimester as recommended (TDHS-MIS, 2016). In Lushoto District, most women (94\%) attend ANC, but only $16 \%$ follow the recommendation schedule (TDHS-MIS, 2016).

\footnotetext{
* Correspondence Email: mlay.joyce@yahoo.com
} 
In Tanzania, different strategies have been undertaken by the government to increase access to antenatal care services including provision of ANC services that are free of charge (Gross et al., 2012). However, most women still delay to make their ANC visits (Nyamtema et al., 2003; Mrisho et al., 2009). This study aimed to determine the prevalence and factors associated with late antenatal visit in Lushoto district in north-eastern Tanzania.

\section{Material and Methods}

\section{Study design}

This was a hospital based cross sectional study, involving pregnant women attending antenatal care clinic at a district hospital in Lushoto, north-eastern Tanzania. The district has an area of $3,500 \mathrm{~km}^{2}$ and a population of 492,441 (URT, 2013). Lushoto district hospital serves about 200 pregnant women in ANC clinic in a month. This study was conducted during August and September 2015.

\section{Sample Size}

Using the formula $n=z^{2} p(100-p) / e^{2}$, marginal error(e) of $4 \%, z$ at $95 \%$ confidence interval of 1.96 , and prevalence of late antenatal clinic booking of $33 \%$ (TDHS, 2011), the sample size was estimated to be 240 participants. Convenience method of sampling was used to enrol study participants. All pregnant women who met the inclusion criteria (a consented pregnant woman with more than 12 weeks of pregnancy) were included in the study. Non consented pregnant women with less than 12 weeks of pregnancy and those who seriously ill were excluded from the study.

\section{Data collection}

Data collection was done daily from Monday to Friday. A convenient method of sampling was used to obtain the study participants. Information about demographic characteristics, antenatal attendance and obstetrics history was obtained through a structured questionnaire and was validated from antenatal card.

\section{Data analysis}

Data from the questionnaire were entered into a computer using SPSS Version 20 followed by data cleaning and generation of frequency distribution tables. Descriptive analysis was done by using frequencies, percentages and means where appropriate. Association between explanatory variable and the outcome of interest was done using $2 \times 2$ tables. Multivariate logistic regression analyses were used to examine independent variables that influence the outcome variable. Odds Ratios with corresponding 95\% confidence interval are presented and $p$ value of less or equal 0.05 was considered statistically significant.

\section{Ethical considerations}

Ethical clearance for conducting the research was obtained from the Institutional Review Board of the Hubert Kairuki Memorial University. Permission to carry out the study was obtained from District and Hospital administration. Informed consent was obtained from each study participant before data collection.

\section{Results}

A total of 240 respondents were recruited into the study. Majority $(\mathrm{N}=215 ; 89.6 \%)$ of the participants were in the age category of $18-35$ years; 155 (64.6\%) had primary level of education; $200(83.3 \%)$ had no employment, and more 203 (81.6\%) (Table1). 
Table 1. Demographic characteristics of the respondents $(n=240)$

\begin{tabular}{llll}
\hline Variable & Response & Frequency & Percent \\
\hline Age & $13-17$ Years & 3 & 1.3 \\
& $18-35$ Years & 215 & 89.6 \\
Education level & $36-45$ Years & 22 & 9.2 \\
& Never been to school & 7 & 2.9 \\
& Primary level & 155 & 64.6 \\
& Secondary level & 48 & 20.0 \\
Occupation & College & 30 & 12.5 \\
\multirow{3}{*}{ Gravidity } & Employed & 40 & 16.7 \\
& Unemployed & 200 & 83.3 \\
Parity & Prime gravida & 93 & 38.5 \\
& Second & 58 & 24.2 \\
Marital status & Multigravida & 89 & 37 \\
& 0 & 96 & 40 \\
& $1-3$ & 130 & 54.2 \\
& $>4$ & 14 & 5.8 \\
\hline
\end{tabular}

\section{First antenatal care visit}

Of the 240 study participants, 169 (70.4\%) booked late. The reasons for late booking included: no illness experienced during pregnancy 39 (16.25\%), 56 (23.3\%)did not know if they were pregnant. Others did not need to book because of being busy 39 (16.25\%) and the remaining 35 (14.58\%) did not know when exactly they were supposed to book.

Table 2. Factors associated with late antenatal care visit ( $\mathrm{n}=169)$

\begin{tabular}{|c|c|c|c|c|c|}
\hline Variable & Response & Late ANC Visit N(\%) & Total N(\%) & Chi-square & P value \\
\hline \multirow[t]{3}{*}{ Age (years) } & $13-17$ & $2(66.7)$ & $3(100)$ & & \\
\hline & $18-35$ & $146(67.9)$ & $215(100)$ & 7.2191 & 0.008 \\
\hline & $36-45$ & $21(95,5)$ & $22(100)$ & & \\
\hline \multirow[t]{3}{*}{ Education level } & None & $6(85.7)$ & 7 & & \\
\hline & Primary & $119(76.8)$ & 155 & 10.724 & 0.013 \\
\hline & Secondary/College & $44(56.4)$ & 78 & & \\
\hline \multirow[t]{2}{*}{ Occupation } & Employed & $17(42.5)$ & 40 & 24.408 & 0.015 \\
\hline & Unemployed & $152(76)$ & 200 & & \\
\hline \multirow[t]{3}{*}{ Gravidity } & Prime gravida & $58(62.4)$ & $93(100)$ & & \\
\hline & second & $35(60.3)$ & $58(100)$ & 7.923 & 0.161 \\
\hline & Multigravida & $76(85.4)$ & $89(100)$ & & \\
\hline \multirow[t]{3}{*}{ Parity } & 0 & $61(63.5)$ & 96 & & \\
\hline & $1-3$ & $94(72.3)$ & 130 & 4.879 & 0.431 \\
\hline & $>4$ & $14(100)$ & 14 & & \\
\hline \multirow[t]{2}{*}{ Marital Status } & Married & $137(67.5)$ & 203 & 5.423 & 0.09 \\
\hline & Not married & $32(86.5)$ & 37 & & \\
\hline \multirow{2}{*}{$\begin{array}{l}\text { Distance } \\
\text { facility }\end{array}$} & Long distance & $47(90.4)$ & $52(100)$ & 13.023 & 0.000 \\
\hline & Short distance & $122(64.9)$ & $188(100)$ & & \\
\hline
\end{tabular}

Various factors were significantly associated with late booking of antenatal visit. They included unmarried status $\left(\chi^{2}=5.423, p=0.009\right)$, unemployment $\left(\chi^{2}=24.408, p=0.015\right)$, low educational level $\left(x^{2}=10.729, p=0.013\right)$, long distance to the health facility $\left(\chi^{2}=13.023, p=0.000\right)$, age 18-35 years and $36-45$ years $\left(\chi^{2}=7.291, p=0.008\right)$ (Table 3$)$. 
Table 3: Multivariate logistic regression table on factors associated with late antenatal visit

\begin{tabular}{lllllll}
\hline Variable & Age & $\begin{array}{l}\text { Late ANC Visit } \\
\mathbf{N}(\%)\end{array}$ & $\begin{array}{l}\text { Total } \\
\mathbf{N}(\%)\end{array}$ & AOR & 95\%Cl & P value \\
\hline Age & 13-17 Years & $2(66.7)$ & $3(100)$ & 1 & & \\
\multirow{4}{*}{ Education } & 18-35 Years & $146(67.9)$ & $215(100)$ & 1.14 & $0.04-2.175$ & 0.141 \\
& $36-45$ Years & $21(95,5)$ & $22(100)$ & 2.29 & $0.101-3.38$ & 0.26 \\
& None & $6(85.7)$ & $7(100)$ & 1 & & \\
\multirow{2}{*}{ Occupation } & Primary level & $119(76.8)$ & $155(100)$ & 0.551 & $0.064-4.728$ & 0.372 \\
& Secondary /College & $44(56.4)$ & $78(100)$ & 0.096 & $0.010-0.910$ & 0.587 \\
\multirow{2}{*}{ Marital status } & Employed & $17(42.5)$ & $40(100)$ & 1 & & \\
\multirow{2}{*}{ Distance to facility } & Unemployed & $152(76)$ & $200(100)$ & 4.284 & $2.115-8.679$ & 0.000 \\
& Married & $137(67.5)$ & $203(100)$ & 1 & & \\
& Not married & $32(86.5)$ & $37(100)$ & 3.083 & $1.149-8.275$ & 0.025 \\
& Long distance & $47(90.4)$ & $52(100)$ & 1 & & \\
& Short distance & $122(64.9)$ & $188(100)$ & 1.197 & $1.075-1.518$ & 0.51 \\
\hline
\end{tabular}

After controlling for potential confounders, factors which were associated with late antenatal visits included unmarried marital status ( $A O R=3.08 ; 95 \% \mathrm{Cl} 1.149-8.275 ; P$-value $=0.025$ ) and unemployment status ( $\mathrm{AOR}=4.28 ; 95 \% \mathrm{Cl} 2.11-8.679 ; p=0.000)$.

\section{Discussion}

Timely and adequate antenatal care is a corner stone for preventing complications during pregnancy. The prevalence of late ANC booking among women in Lushoto district was high. Similar higher prevalence of late first ANC attendance has been reported in Zambia (Banda et al., 2012; Chewe et al., 2016), Uganda (Kiwuwa \& Mufubenga, 2008) and Nigeria (Uji et al., 2017). However, we observed a slightly lower prevalence than that reported by Adekanle \& Isawumi (2008) in western Nigeria. The observed difference might be reflecting a relative good community sensitization on reproductive and child health in our setting.

Various factors were associated with this high prevalence of late ANC booking one of which being old maternal age. Women aged over 35 years were more likely to present themselves late for the first antenatal visit, this is possibly due to the facts that this group of women have other children and therefore they perceive themselves to be experienced in antenatal care and therefore they are reluctant to make a timely booking. In a study in Nigeria, about two thirds of the women book late it is due to ignorance or misconceptions of the purpose of, and right time to commence antenatal care (Ndidi \& Oseremen, 2010).

The present study demonstrated that women with higher education levels were more likely to initiate ANC early compared to those without. Similar findings have been reported by Tariku et al. (2010) whereby women who were well informed about ANC were more likely to book for ANC within the recommended time. The other factor that was associated with late antenatal visit was unmarried marital status. This study shows that majority of respondents who were not married made their first visit late. The late booking therefore is likely to be attributed to the lack of financial support from partners which discourage women from seeking early ANC services. Despite the fact that antenatal services in Tanzania are provided for free, women still need financial capacity to support their daily living. These women may be busy with economic activities to cater for their families and therefore they fail to book timely for ANC. In a recent study in Zambia, age, marital status and parity were found to be the main factors associated with late ANC booking (Chewe et al., 2016). In a study in Nigeria, ignorance and financial constraints were reported to be the underlying factors in late ANC booking (Gharoro \& Igbafe, 2000).

The study showed that women who had never been to school were more likely to attend antenatal care visits late compared to woman with other levels of education. This can be explained by the fact that women with very low level of education might have inadequate knowledge on 
importance of early antenatal visit. Other factors like gravidity and parity were not significant associated with late first ANC visit. However, multigravidae were more likely to book ANC visits late compared to other levels of gravity. Multigravida women may have perceived themselves to have more experience about pregnant issues and therefore could not see the necessity of making an early and timely booking.

In conclusion, the prevalence of late first antenatal visit was found to be very high in Lushoto; mainly due to unmarried and unemployment status. Therefore, provision of continuous health education and community sensitization on the importance of timely seeking for ANC services should be strengthened.

\section{References}

Adekanle, D.A. \& Isawumi, A.I. (2008) Late antenatal care booking and its predictors among pregnant women in south western Nigeria, Journal of Health and Allied Sciences 7 (4): 1-6.

Banda, I., Michelo, C. \& Hazemba, A. (2012) Attendance in selected rural and urban communities of the Copperbelt Province of Zambia. Medical Journal of Zambia 39: $3 \mathrm{Co}$.

Chewe, M.M., Muleya, M.C. \& Maimbolwa, M. (2016) Factors associated with late antenatal care booking among pregnant women in Ndola District, Zambia. African Journal of Midwifery and Women's Health 10 (1).

Collin, S.M., Anwar, I. \& Ronsmans, C. (2007) A decade of inequality in maternity care: antenatal care, professional attendance at delivery, and caesarean section Bangladesh; 1991-2004, http://www.equityhealthj.com/content/6/1/9 Biomedical Central

Ebu, N.A. \& Gross, J. (2015) Factors influencing access to antenatal services and delivery care in sub Saharan Africa. African Journal of Midwifery and Women's Health 9:2.

Gharoro, E.P. \& Igbafe, A.A. (2000) Antenatal care: some characteristics of the booking visit in a major Teaching hospital in the developing world. Medical Science Monitor 6: 519-522.

Gross, K., Alba, S., Glass, R.T., Schellenberg, J.A. \& Obrist, J. (2012) Timing of antenatal care for adolescent and adult pregnant women in south-eastern Tanzania. BMC Pregnancy and Childbirth 12:16.

Kisuule, I., Kange, D.K., Najjuka, F., Kssematimba, S., Arinda, A., Nakitende, G. \& Otim, L. ( 2013) Timing and reasons for coming late for the first antenatal care visit by pregnant women at Mulago Hospital, Kampala, Uganda. BMC Pregnancy and Childbirth 13(1): 6-7.

Kiwuwa, M.S. \& Mufubenga, P. (2008) Use of antenatal care, maternity services, intermittent presumptive treatment and insecticide treated nets by pregnant women in Luwero district, Uganda. Malar Journal 7:44.

MoH (2002) Focused Antenatal Care, Malaria and Syphilis in Pregnancy. Orientation Package for Service Providers. Ministry of Health and Social Welfare, Dar es Salaam, Tanzania.

Mrisho, M., Obrist, B., Schellenberg, A.J., Haws, R.A., Mushi, A.K., Mshinda, H., Tanner, M. \& Schellengberg, D. (2000. The use of antenatal and postnatal care: perspectives and experiences of women and health care providers in rural southern Tanzania. BMC Pregnancy Childbirth 9:10.

Ndidi, E.P. \& Oseremen, I.G. (2010) Reasons Given by Pregnant Women for Late Initiation of Antenatal Care in the Niger Delta, Nigeria. Ghana Medical Journal 44: 47-51.

Nisar, N. \& White, F. (2003) Factors affecting utilization of antenatal care among reproductive age group women (15-49 years) in an urban squatter settlement of Karachi. Journal of the Pakistan Medical Association 53: 47-53.

Nyamtema, A.S., Urassa, D.P. \& van Roosmalen, J. (2011) Maternal health interventions in resource limited countries: a systematic review of packages, impacts and factors for change. Pregnancy Childbirth 11: 30. 
Say, L., Chou, D., Gemmill, A., Tuncalp, Ö, Moller, A.B., Daniels, J., Gülmezoglu, A.M., Temmerman, M. \& Alkema, L. (2014) Global Causes of Maternal death: A WHO Systematic Analysis. Lancet Global Health 2: e323-e333.

Tariku, A., Melkamu, Y. \& Kebede Z. (2010) Previous utilization of service does not improve timely booking in antenatal care: Cross sectional study on timing of antenatal care booking at public health facilities in Addis Ababa. Ethiopian Journal Health Development 24: 226-233.

TDH-MIS (2016) Tanzania Demographic and Health Survey and Malaria Indicator Survey. Ministry of Helath, Community Development, Gender, Elderly and Children (Tanzania Mainland), Ministry of Health (Zanzibar), National Bureau of Statistics, Office of the Chief Government Statistician, and ICF. Dar es Salaam, Tanzania and Rockville, Maryland, USA.

TDHS (2011) Tanzania Demographic and Health Survey 2010-11. National Bureau of Statistics and ICF Macro. Calverton, Maryland, USA.

Uji, A.B., Efiok, E.E., Etenikang, A.S., Obinna, N.C., Chinedum, N.E. \& Egor, O.S. (2017) Obstetric characteristics of women attending antenatal clinic in a tertiary hospital in Nigeria. Sky Journal of Medicine and Medical Sciences 5(2): 15-19.

WHO (2006) Provision of Focused Antenatal Care for Pregnant Women. World Health Organization, Geneva. 